\title{
Empreendedores de políticas públicas na implementação de programas governamentais
}

\author{
Maria Lúcia de Oliveira Feliciano de Lima \\ Tribunal de Contas da União \\ Janann Joslin Medeiros \\ Universidade de Brasília
}

\begin{abstract}
Este artigo traz novo olhar para a implementação de programas governamentais, aproximando as literaturas de políticas públicas, implementação e inovação. Procurou-se investigar a forma de atuação de diretoras de escolas do Distrito Federal na implementação de dois programas distritais. Foi evidenciado que há, entre as entrevistadas, pessoas que se aproximam de champions e de empreendedores de políticas públicas e que há características que diferenciam implementadores empreendedores de não empreendedores. Foram encontradas semelhanças entre os conceitos de champions, empreendedores de políticas públicas e implementadores de programas, assim como há pontos em comum entre as fases de inovação e as etapas do ciclo de políticas públicas. Essas semelhanças abrem a possibilidade de diálogo frutífero entre esses dois campos de estudo e possibilita a ampliação dos estudos sobre implementação.
\end{abstract}

Palavras-chave: implementação; implementação de programas educacionais; empreendedores de políticas públicas; champion.

Emprendedores de políticas públicas en la implementación de programas gubernamentales Este artículo trae una nueva mirada a la implementación de programas gubernamentales, aproximando las literaturas de políticas públicas, implementación e innovación. Se buscó identificar la forma de actuación de directoras de escuelas del Districto Federal en la implementación de dos programas distritales. Se ha evidenciado que hay, entre las entrevistadas, personas que se aproximan de champions y de emprendedores de políticas públicas y que hay características que diferencian implementadores emprendedores de no emprendedores. Se concluyó que hay similitudes entre los conceptos de champions, emprendedores e implementadores, así como hay puntos en común entre las fases de innovación y las etapas del ciclo de políticas públicas. Esas similitudes posibilitan diálogo entre eses dos campos de estudio y la ampliación de estudios acerca de implementación.

Artigo recebido em 3 maio 2011 e aceito em 15 jun. 2012. 
Palabras clave: implementación; implementación de programas educacionales; emprendedores de políticas públicas; champion.

\section{Entrepreneurs of public policies in the implementation of government programs}

This study takes a new look at the question of policy implementation, bringing together concepts from the literatures of public policy, implementation and innovation to investigate the actions undertaken by school directors to implement education programs. Among the interviewees there are those whose actions approximate those characteristic of champions in the innovation literature, and public policy entrepreneurs in the public policy literature; and characteristics were found that differentiate implementation entrepreneurs or champions from non-entrepreneurs. Similarities were found between the concepts of champion and policy entrepreneur, as well as points in common between the phases of innovation and the phases of the policy cycle, opening the possibility for fruitful dialogue between the two fields of study and for enhancing studies of program and policy implementation.

KEY WORDs: program implementation; implementation of education programs; policy entrepreneurs; champions.

\section{Introdução}

A pesquisa descrita neste artigo foi motivada pela constatação de uma das autoras, no exercício de sua profissão, de que um dos fatores que influenciam e que fazem diferença na implementação de programas governamentais é a atuação dos agentes que interagem diretamente com os cidadãos e que têm grande discricionariedade na execução de suas tarefas. Essa constatação despertou o interesse de verificar, por meio de um trabalho acadêmico, quais são as características que fazem com que um implementador de programas de governo se destaque e seja bem-sucedido.

Os programas governamentais brasileiros são formulados de maneira centralizada e definidos para ser implementados de forma homogênea em todo o Brasil. Entretanto, constata-se com frequência que a implementação desses programas varia muito, dependendo da localidade. Municípios semelhantes, considerando a região geográfica, a extensão, as características populacionais e a quantidade de recursos financeiros, muitas vezes diferem bastante com relação ao grau de implementação dos programas governamentais. Ao buscar razões para isso, deparou-se com a possibilidade de que essa diferença poderia ser explicada, entre outros fatores, pelos conceitos de empreendedor de políticas públicas e do champion de projetos de inovação.

A pesquisa teve por objetivo, portanto, verificar e descrever que características associadas com esses conceitos são encontradas em implementadores de programas governamentais brasileiros. Para isso, inicialmente, foram identificadas, na literatura, as características e a forma de atuação de champions e de empreendedores de políticas públicas. Buscou-se, em especial, literatura brasileira sobre os temas. Porém, há poucos trabalhos sobre implementação e não foram encontrados estudos brasileiros sobre champions. 
A partir da coleta de dados, as características e a forma de atuação dos implementadores de programas governamentais foram identificadas e descritas. Essas características foram comparadas e contrastadas com as características identificadas na literatura.

O artigo traz novo olhar para a implementação de políticas públicas, aproximando as literaturas de políticas públicas, implementação e inovação.

Além desta introdução, o artigo compõe-se de mais oito partes. As partes dois a seis tratam de formulações teóricas sobre políticas públicas, implementação de programas governamentais, inovação, champions, empreendedores de políticas públicas, gestores eficazes e street-level bureaucrats. A sétima parte descreve o método adotado nesta pesquisa, seguida da oitava parte, que sintetiza os resultados obtidos e a respectiva discussão. Por fim, apresentamse as conclusões e as sugestões de novos trabalhos.

\section{Políticas públicas}

Souza (2007:68) afirma que não existe só uma definição de políticas públicas e nem a melhor definição. Ela pondera que política pública é "o campo do conhecimento que busca, ao mesmo tempo, colocar o 'governo em ação’ e/ou analisar essa ação (variável independente) e, quando necessário, propor mudanças no rumo ou curso dessas ações (variável dependente)”.

De maneira semelhante, para Oszlak e O’Donnell (1976:21, tradução nossa), uma política pública é:

[...] um conjunto de ações e omissões que manifestam uma modalidade de intervenção do Estado em relação a uma questão que chama a atenção, o interesse e a mobilização de outros atores da sociedade civil. Desta intervenção, pode-se inferir uma determinada direção, uma determinada orientação normativa, que, presumivelmente, afetará o futuro curso do processo social desenvolvido, até então, em torno do tema.

O ciclo de políticas públicas envolve várias etapas, cuja quantidade e classificação variam entre os autores. Entretanto, embora haja algumas diferenças de nomenclatura, as etapas mais comumente encontradas na literatura são: formulação, implementação e controle (ou avaliação) (Frey, 2000).

Para Theodoulou (1995), a formulação da política é a criação de cursos de ação relevantes e factíveis para lidar com problemas. Segundo Souza (2006:26), "a formulação de políticas públicas constitui-se no estágio em que os governos democráticos traduzem seus propósitos e plataformas eleitorais em programas e ações que produzirão resultados ou mudanças no mundo real".

A implementação, foco principal de interesse no presente artigo, é descrita com maior detalhamento na próxima seção. Pode ser definida como "o que acontece entre as expectativas da política e seus resultados percebidos" (Hill e Hupe, 2002:2, tradução nossa). 
Finalmente, a avaliação, segundo Weiss (1998:4, tradução nossa), é uma "análise sistemática do processo e/ou dos resultados de um programa ou de uma política, comparados com um conjunto de padrões, com o objetivo de contribuir para a melhoria deste programa ou desta política". É a última etapa do ciclo de políticas públicas e tem três finalidades: aquilatar os resultados de um curso de ação que se encerra; fornecer elementos para o desenho de novas intervenções ou para o aprimoramento de políticas e programas em curso; ser elemento central da accountability (Faria, 2005). Theodoulou (1995) e Menicucci (2007) ressaltam que a avaliação não precisa ser feita após a implementação ela pode ocorrer, e de fato ocorre, durante todo o ciclo das políticas públicas.

\section{Implementação de programas governamentais}

A obra pioneira sobre implementação é o livro Implementation: how great expectations in Washington are dashed in Oakland, de Pressman e Wildavsky, publicado em 1973. Nele, os autores definem implementação como "um processo de interação entre o estabelecimento de objetivos e as ações realizadas para atingi-los" (Pressman e Wildavsky, 1973:xxiii, tradução nossa). Eles descreveram detalhadamente o processo de implementação de programas de capacitação e melhoria de serviços públicos em Oakland, na Califórnia (EUA), e pretenderam mostrar o perigo de distanciar a formulação de uma política pública de sua implementação, além das diversas dificuldades existentes para que essa implementação seja bem-sucedida, decorrentes de inúmeros pontos de decisão e da multiplicidade de atores envolvidos, mesmo quando as condições são favoráveis. Os autores consideraram impressionante que algum programa federal ainda consiga ser bem-sucedido (Pressman e Wildavsky, 1973).

Parafraseando Pressman e Wildavsky, Exworthy, Berney e Powell (2002) publicaram um artigo intitulado How great expectations in Westminster may be dashed locally: the local implementation of national policy on health inequalities. Nele, os autores discorrem sobre as dificuldades para implementar, no Serviço Nacional de Saúde do Reino Unido (National Health Service - NHS), programa com o objetivo de aumentar a equidade na saúde. Eles concluíram que as expectativas foram frustradas tanto em nível central quanto em nível local devido a três fatores: a lacuna de implementação (diferença entre o formulado pelo nível central e o executado pelo implementador local); a falta de condições fornecidas pelo nível central para que as atividades fossem implantadas na ponta; fatores políticos que dificultaram que os empreendedores da política (policy entrepreneurs) pudessem garantir que a equidade se mantivesse na agenda.

Bardach (1977:9, tradução nossa) refere-se à implementação como "um processo de interação estratégica entre numerosos interessados que buscam alcançar seus próprios objetivos, que podem ou não ser compatíveis com os objetivos estabelecidos na formulação da política". Por meio de uma tipologia de jogos, Bardach descreve os diversos empecilhos e dificuldades encontrados na implementação e afirma que seu livro "não é otimista".

Ollaik e Medeiros (2011) afirmam que, segundo a literatura sobre o assunto, a implementação perfeita é inatingível. Para que houvesse a possibilidade de uma implementação perfeita, diversas precondições (impossíveis no mundo real) seriam necessárias. Ainda que 
essas condições existissem, o ponto-chave de qualquer implementação é o comportamento humano. Tal destaque ao comportamento humano interessa diretamente ao trabalho descrito neste artigo, pois se pretendeu entender o papel da atuação de indivíduos na implementação de programas de governo.

Com a evolução das pesquisas sobre implementação, surgiram duas perspectivas para estudar o fenômeno, denominadas top-down e bottom-up. Os defensores da escola top-down veem os formuladores da política como os atores centrais e concentram a atenção nos fatores que podem ser manipulados no nível central. Esses defensores acreditam que o processo pode ser controlado de cima para baixo e consideram que a implementação foi bem-sucedida se as ações oficiais foram implementadas e o público-alvo coincidiu com o definido durante a formulação. As principais orientações da escola top-down são: definir políticas claras e consistentes, minimizar a quantidade de atores envolvidos, diminuir a necessidade de mudanças, encarregar da implementação alguém que concorde com as diretrizes da política. Os principais representantes da escola top-down são: Pressman e Wildavsky, Mazmanian e Sabatier, Van Meter e Van Horn, Bardach, Hogwood e Gunn (Hill e Hupe, 2002; Matland, 1995; Oliveira, 2006).

Em oposição à abordagem top-down, os defensores da escola bottom-up consideram que se entende melhor a implementação da política olhando-a do ponto de vista daqueles que estão mais próximos às ações resultantes delas. Argumentam que a política realmente se concretiza em nível local e que os burocratas da linha de frente (street-level bureaucrats) poderiam e deveriam influenciar mais o processo. Os defensores da abordagem bottom-up afirmam que o sucesso na implementação de uma política depende, em grande parte, das habilidades dos implementadores locais. Se eles não tiverem liberdade para adaptar a política às condições locais, ela estará fadada ao insucesso. Os principais representantes da escola bottom-up são: Lipsky, Berman, Hjern, Porter, Hull, Barrett e Fudge (Matland, 1995; Hill e Hupe, 2002; Oliveira, 2006).

Com a evolução dos estudos sobre implementação, concluiu-se que o mais adequado é a convergência das duas perspectivas, unindo as variáveis macro dos modelos top-down com as variáveis micro dos modelos bottom-up (Matland, 1995; Hill e Hupe, 2002).

\section{Inovação}

Inovação é um tema importante neste artigo porque, conforme será visto, há pontos de intersecção entre os processos de inovação e de políticas públicas. Especificamente, há semelhanças entre as fases do processo de inovação e as etapas do ciclo de políticas públicas. Também chama a atenção o fato de que a inovação enfatiza a figura do champion, que é uma espécie de empreendedor de inovação, enquanto existe na literatura de políticas públicas a figura do empreendedor de políticas, que - como será detalhado - tem características similares às dos champions.

A definição de inovação é ampla. Inovação "é uma ideia, prática ou objeto percebido como novo por um indivíduo ou outra unidade que resolva adotá-la" (Rogers, 1995:11, tradução nossa). Segundo o autor, se a ideia parece nova para o indivíduo, é uma inovação e não necessariamente precisa envolver novas tecnologias. 
Há autores que usam o termo implementação para definir inovação. Por exemplo, Neves e Neves (2011:482) afirmam que, no Relatório do Global Innovation Index, inovação é definida como "a implementação de um novo produto ou um produto melhorado significativamente (bens ou serviços), um novo processo, um novo método de marketing, ou um novo método organizacional [...]”. De maneira similar, Spink (2006:25) define inovação na gestão pública como "uma mudança substancial, quantitativa ou qualitativa, nas práticas e estratégias anteriores [...] mediante a implementação de um novo programa ou conjunto de atividades ou na melhoria significativa das atividades ou programas existentes".

Assim como para o ciclo de políticas públicas, também não há unanimidade no que se refere às fases da inovação. Segundo Rogers (1995), o processo de decisão da inovação é formado por cinco estágios que se referem ao indivíduo ou a outra unidade de decisão: conhecimento (quando se sabe da existência da inovação e de como ela funciona); persuasão (quando se forma atitude favorável ou desfavorável à inovação); decisão (quando são realizadas atividades que levarão a adotar ou rejeitar a inovação); implementação (quando a inovação passa a ser usada); confirmação (quando se decide se a inovação continuará ou não sendo usada).

Como mencionado, as fases da inovação se assemelham às fases do ciclo de políticas públicas. Comparam-se, no quadro 1, esses cinco estágios da inovação propostos por Rogers (1995) com as seis fases do ciclo de políticas públicas apontadas por Souza (2007): definição de agenda, identificação de alternativas, avaliação das opções, seleção das opções, implementação e avaliação.

A semelhança entre as fases da inovação e as fases do ciclo de políticas públicas é sugestiva, apontando a possibilidade de ampliar e aproximar os campos de estudos sobre os dois temas (inovação e políticas públicas) e de que os resultados e conclusões de uma área possam ser, em algumas situações, aproveitados pela outra (sempre considerando as peculiaridades e o contexto de cada estudo).

Quadro 1

Fases da inovação e do ciclo de políticas públicas

\begin{tabular}{|c|c|c|}
\hline Autores & $\begin{array}{c}\text { Inovação } \\
\text { Rogers (1995) }\end{array}$ & $\begin{array}{l}\text { Políticas públicas } \\
\text { Souza (2007) }\end{array}$ \\
\hline \multirow{5}{*}{ Fases } & Conhecimento & $\begin{array}{c}\text { Definição de agenda } \\
\text { Identificação de alternativas }\end{array}$ \\
\hline & Persuasão & Avaliação das opções \\
\hline & Decisão & Seleção das opções \\
\hline & Implementação & Implementação \\
\hline & Confirmação & Avaliação \\
\hline
\end{tabular}

Fonte: Rogers (1995) e Souza (2007). 


\section{Champions, empreendedores de políticas públicas e gestores eficazes}

Os estudiosos da área de inovação e de mudança organizacional referem-se frequentemente aos champions, que seriam aqueles que se envolvem pessoalmente na implantação de uma ideia inovadora, inclusive assumindo riscos, e buscam apoio junto aos integrantes da organização para a ideia (Schon, apud Markham, 1998; Chakrabarti, 1974; Shane, Venkataraman e Macmillan, 1995; Markham e Griffin, 1998; Bryson, Crosby e Stone, 2006).

Howell, Shea e Higgins (2005) desenvolveram e validaram instrumento para identificar o comportamento dos champions. A partir de seu trabalho, chegaram a um conjunto de 15 itens que refletiriam esse comportamento: 1) promover entusiasticamente as vantagens da inovação; 2) expressar convicções fortes sobre a inovação; 3) demonstrar confiança sobre o que a inovação pode trazer; 4) mostrar otimismo sobre o sucesso da inovação; 5) apontar razões pelas quais a inovação será bem-sucedida; 6) não parar de incentivar entusiasticamente; 7) persistir; 8) mostrar tenacidade na superação de obstáculos; 9) continuar envolvido com a inovação até que ela seja implementada; 10) derrubar as barreiras à inovação; 11) não desistir quando outros disserem que não pode ser feito; 12) persistir diante das adversidades; 13) entregar os problemas a quem possa resolvê-los; 14) conseguir o envolvimento das pessoas certas; 15) conseguir o envolvimento das pessoas que tomam decisões.

O conceito de policy entrepreneur, aqui traduzido como empreendedor de políticas públicas, apresenta fortes similaridades com o conceito de champion. Uma das principais referências na área de empreendedor de política é Kingdon. Em seu livro Agendas, alternatives, and public policies, o autor descreve os empreendedores de política como "advogados que estão dispostos a investir seus recursos - tempo, energia, reputação e dinheiro — na esperança de obter futuros benefícios" e acrescenta que eles podem ser encontrados em muitos locais, tanto em posições formais quanto informais, tanto dentro quanto fora do governo (Kingdon, 1995:122 e 179, tradução nossa).

Kingdon (1995) afirma que, em estudos de caso, quase sempre é possível identificar uma pessoa, ou um grupo de pessoas que são fundamentais para fazer com que determinado assunto tenha destaque na agenda política e em sua aprovação. O autor destaca algumas características que contribuem para o sucesso dos empreendedores: fazer com que suas reivindicações sejam ouvidas e consideradas; ter conexões políticas e capacidade de negociação; ser persistente (provavelmente a mais importante, na opinião de Kingdon). Além disso, o empreendedor de política está sempre pronto para "enfrentar a situação que aparecer" e encarar cada crise como uma oportunidade (Kingdon, 1995). Kingdon afirma que a definição da agenda governamental é função de três fluxos: problemas, policies (políticas públicas) e politics (atividade política). E que é papel do empreendedor juntar esses três fluxos. Zahariadis (2003) mostrou a existência desses fluxos e também se referiu à ação empreendedora de unir esses fluxos, não só na fase de formação de agenda, mas também em outras etapas das políticas públicas.

Bartlett e Dibben (2002:109, tradução nossa) afirmam haver "um link óbvio entre inovação no setor público e empreendedores públicos", dizem que as atribuições dos champions 
aproximam-se das atribuições dos empreendedores no setor público e enfatizam a importância das habilidades e atitudes dos champions na implementação da inovação. Corroborando essa opinião, tem-se Windrum e Koch (2008), que usam a mesma definição de empreendedor público adotada por Kingdon e dizem que inovações são abundantes em serviços do setor público.

Finalmente, é possível observar semelhanças dos conceitos de champion e de empreendedor de políticas públicas com o de gestor eficaz. Ao tratar de eficácia gerencial, Mintzberg (2010) usa como metáfora a confecção de uma tapeçaria. Os fios condutores (ou disposições mentais) que ele descreve para a gestão eficaz revelam-se muito parecidos com as características de champions identificadas por Howell, Shea e Higgins (2005) e de empreendedores de políticas públicas apresentadas por Kingdon (1995) e Zahariadis (2003).

O primeiro fio descrito por Mintzberg (2010:211-220) é o fio energético, que seria “a enorme quantidade de energia que os gerentes eficazes põem em seu trabalho". O fio reflexivo relaciona-se a saber "aprender com a própria experiência", explorar diversas opções e tentar outra abordagem quando a primeira não funciona. O fio analítico refere-se a manter equilíbrio entre conhecimento formal e explícito e informal e tácito; entre análise e intuição. O fio de visão de mundo refere-se a cruzar os limites do seu próprio mundo e conhecer os mundos de outras pessoas. O fio colaborativo trata de fazer vir à tona a energia positiva que existe nas pessoas e deixá-las colaborar, em vez de controlá-las. O fio proativo é aquele em que há equilíbrio entre reflexão e ação. Segundo Mintzberg, os gerentes eficazes são agentes de mudança, e não alvo dela. Eles "seguem o fluxo, mas também criam o fluxo". Por fim, tudo converge para o fio integrativo. "A gestão é uma tapeçaria tecida a partir dos fios da reflexão, análise, mundanidade, colaboração e proatividade, todos os quais são infundidos com energia pessoal e unidos pela integração social."

\section{Implementadores de programas governamentais/Street-level bureaucrats}

Lipsky (1980) discorre longamente sobre os burocratas da linha de frente (street-level bureaucrats), ou seja, as pessoas que implementam as políticas públicas, aquelas que estão em contato direto com os usuários dessas políticas, tais como professores, policiais, médicos, assistentes sociais. $\mathrm{O}$ autor afirma que esses implementadores dispõem de altos graus de discricionariedade e de relativa autonomia no que se refere à implementação dessas atividades, ou seja, eles têm a possibilidade de não executá-las da forma como elas foram pensadas e imaginadas pelos formuladores da política. E, na maioria das vezes, isso acontece. Em última análise, quem faz a política são os burocratas de linha de frente, eles estabelecem, na prática, os limites da intervenção estatal.

Perez (2010:1191) faz afirmação no mesmo sentido, quando diz que "alguns autores têm destacado que a participação das pessoas/implementadores em diversas comunidades e grupos de relacionamentos é essencial para a implementação".

A partir das informações sobre atribuições, funções e dificuldades dos burocratas de linha de frente, percebe-se a importância deles e de suas características e atuação para o pro- 
cesso de implementação de políticas públicas e o potencial deles de ser champions ou não da implementação dos programas governamentais em nível local.

\section{Método}

A pesquisa realizada é descritiva, exploratória e de natureza qualitativa. A intenção foi identificar e descrever, na implementação dos programas Bloco Inicial de Alfabetização (BIA) e Ciência em Foco (CF) do Distrito Federal, as tarefas das diretoras de escola e o contexto em que se encontram, bem como identificar eventuais comportamentos e atitudes que demonstrassem, entre essas diretoras, a existência de características de empreendedores de políticas públicas. A estratégia usada foi o estudo de casos múltiplos. Escolheu-se a diretora da escola para unidade de observação porque, devido às suas atribuições e funções como implementadora de programas educacionais, ela poderia reunir as características de empreendedor encontradas na literatura.

O estudo é transversal e, para sua realização, foram usados dados primários e secundários. Os dados primários são provenientes de entrevistas semiestruturadas com representante da secretaria de educação do Distrito Federal, três dirigentes das Diretorias Regionais de Ensino e nove diretoras de escolas. As diretoras entrevistadas foram escolhidas com base na localização da escola e na indicação dos dirigentes acerca da gestão escolar. Os dados secundários foram obtidos em documentos e trabalhos acadêmicos sobre os programas estudados.

A técnica de análise usada foi a análise de conteúdo das entrevistas, comparando e contrastando as informações obtidas com as características identificadas no referencial teórico. As categorias de análise usadas, seus códigos e suas definições estão apresentados no quadro 2, construída a partir da compilação das características de empreendedores de políticas públicas, champions e gestores eficazes obtidas na literatura.

Quadro 2

Categorias de análise

\begin{tabular}{|c|c|c|c|}
\hline Código & Característica & Definição & Referência \\
\hline 1 & Energia & $\begin{array}{l}\text { Força moral; firmeza; vigor; força (Holanda Fer- } \\
\text { reira, 1975) }\end{array}$ & $\begin{array}{l}\text { Mintzberg (2010); Kingdon } \\
\text { (1995); Kobrak (1996) }\end{array}$ \\
\hline 2 & Entusiasmo & $\begin{array}{l}\text { Exaltação criadora, inspiração, dedicação ardente } \\
\text { (Holanda Ferreira, 1975) }\end{array}$ & $\begin{array}{l}\text { Howell, Shea e Higgins (2005) } \\
\text { Kobrak (1996) }\end{array}$ \\
\hline 3 & Confiança/otimismo & $\begin{array}{l}\text { Crédito, fé, esperança firme, achar que tudo vai } \\
\text { bem, encarar cada crise como uma oportunidade } \\
\text { (Holanda Ferreira, 1975); (Kingdon, 1995) }\end{array}$ & $\begin{array}{l}\text { Howell, Shea e Higgins (2005) } \\
\text { Kingdon (1995) }\end{array}$ \\
\hline 4 & Tenacidade/persistência & $\begin{array}{l}\text { Constância, afinco, insistência, não desistência } \\
\text { frente às adversidades (Holanda Ferreira, 1975) }\end{array}$ & Howell, Shea e Higgins (2005) \\
\hline 5 & Conhecimento técnico & $\begin{array}{l}\text { Detenção de informações e experiências sobre } \\
\text { determinado assunto (Holanda Ferreira, 1975) }\end{array}$ & $\begin{array}{l}\text { Kobrak (1996); Chakrabarti } \\
\text { (1974) }\end{array}$ \\
\hline
\end{tabular}




\begin{tabular}{|c|c|c|c|}
\hline Código & Característica & Definição & Referência \\
\hline 6 & Proatividade & $\begin{array}{l}\text { Tomar iniciativa; iniciar a ação em vez de reagir ao } \\
\text { que acontece; ser agente de mudança; explorar } \\
\text { o contexto ao invés de ser explorado por ele } \\
\text { (Mintzberg, 2010); (Zahariadis, 2003) }\end{array}$ & $\begin{array}{l}\text { Mintzberg (2010); Zahariadis } \\
\text { (2003) }\end{array}$ \\
\hline 7 & $\begin{array}{l}\text { Disposição para assumir } \\
\text { riscos }\end{array}$ & $\begin{array}{l}\text { Propensão, intenção de tomar para si a responsabi- } \\
\text { lidade por possíveis danos ou insucessos (Holanda } \\
\text { Ferreira, 1975) }\end{array}$ & $\begin{array}{l}\text { Markham (1998); Shane, Venka- } \\
\text { taraman e Macmillan (1995); } \\
\text { Chakrabarti (1974) }\end{array}$ \\
\hline 8 & Comprometimento & $\begin{array}{l}\text { Assunção de responsabilidade, empenho (Holan- } \\
\text { da Ferreira, 1975) }\end{array}$ & $\begin{array}{l}\text { Howell, Shea e Higgins (2005); } \\
\text { Kingdon (1995); Kobrak (1996) }\end{array}$ \\
\hline 9 & Criatividade & $\begin{array}{l}\text { Capacidade de criar, inventar, imaginar (Holanda } \\
\text { Ferreira, 1975) }\end{array}$ & Kobrak (1996) \\
\hline 10 & Visão de mundo & $\begin{array}{l}\text { Experiência de vida, perspectiva sobre como o } \\
\text { mundo funciona (Mintzberg, 2010) }\end{array}$ & Mintzberg (2010) \\
\hline 11 & Jogo de cintura & $\begin{array}{l}\text { Flexibilidade na solução de problemas ou situações } \\
\text { difíceis (Holanda Ferreira, 1975) }\end{array}$ & $\begin{array}{l}\text { Kobrak (1996); Mintzberg } \\
(2010)\end{array}$ \\
\hline 12 & $\begin{array}{l}\text { Equilíbrio entre análise e } \\
\text { intuição }\end{array}$ & $\begin{array}{l}\text { Conciliação entre o conhecimento formal e explíci- } \\
\text { to e o informal e tácito (Mintzberg, 2010) }\end{array}$ & Mintzberg (2010) \\
\hline 13 & Espírito colaborativo & $\begin{array}{l}\text { Capacidade de relacionar-se com as pessoas e } \\
\text { de ajudá-las a trabalhar em equipe (Mintzberg, } \\
\text { 2010) }\end{array}$ & Mintzberg (2010) \\
\hline 14 & Espírito integrativo & $\begin{array}{l}\text { Capacidade de enxergar o todo, de produzir equi- } \\
\text { líbrio dinâmico (Mintzberg, 2010) }\end{array}$ & Mintzberg (2010) \\
\hline 15 & Capacidade de delegação & $\begin{array}{l}\text { Capacidade de entregar problemas para quem } \\
\text { pode resolvê-los (Howell, Shea e Higgins, 2005) }\end{array}$ & Howell, Shea e Higgins (2005) \\
\hline 16 & Habilidade política & $\begin{array}{l}\text { Capacidade de envolver quem decide (Howell; } \\
\text { Shea e Higgins, 2005) }\end{array}$ & $\begin{array}{l}\text { Howell, Shea e Higgins (2005); Ko- } \\
\text { brak (1996); Chakrabarti (1974) }\end{array}$ \\
\hline
\end{tabular}

Fonte: Elaboração dos autores.

Para cada característica foram atribuídos dois códigos. Não há ordem de importância ou prioridade na atribuição desses códigos. O código composto apenas por um número refere-se à presença da característica no trecho selecionado. O código composto pela letra "N" seguida de um número refere-se à presença do inverso da característica no trecho selecionado. Por exemplo, o código 2 refere-se a entusiasmo. O código N2 refere-se a falta de entusiasmo. Então, o seguinte trecho de uma entrevista ("A minha avaliação é que, apesar do trabalho, vale a pena!") é identificado com o código 2. O trecho ("Você vai ter só resposta negativa!") é marcado com o código N2.

Apresentam-se, a seguir, os resultados auferidos da pesquisa. 


\section{Resultados e discussão}

A Secretaria de Estado de Educação do Distrito Federal (SEDF) é um órgão da administração direta do governo do Distrito Federal. Suas atribuições e competências estão descritas no Regimento Interno da SEDF. Entre as áreas de atuação da secretaria, destaca-se a educação básica, que compreende a educação infantil, o ensino fundamental e o ensino médio. Compõem a estrutura da SEDF 14 Diretorias Regionais de Ensino (DRE), que têm, entre outras competências, de realizar a interlocução entre a administração central da SEDF e as instituições educacionais integrantes da Rede Pública de Ensino do Distrito Federal. Em cada DRE há um Núcleo de Monitoramento Pedagógico, a quem cabe acompanhar, junto às instituições educacionais, a implementação dos programas BIA e CF (Distrito Federal, 2009).

O BIA tem por objetivo geral "reestruturar o ensino fundamental para nove anos, garantindo à criança a partir de seis anos de idade a aquisição da alfabetização/letramento, bem como seu desenvolvimento integral pautado na ludicidade" (Distrito Federal, 2005:12). Com isso, os responsáveis pela secretaria de educação do Distrito Federal pretendem "promover a progressão continuada do processo de aprendizagem, além de possibilitar à criança a organização de um tempo maior e mais flexível para o desenvolvimento das competências que precisa construir" (Distrito Federal, 2005:4).

O programa CF tem como principal objetivo promover a inclusão científica e tecnológica de crianças e jovens. A principal característica do programa é "trabalhar os conteúdos das ciências naturais no ensino fundamental de forma inovadora". Está articulado em torno de três eixos: confecção e distribuição de materiais de apoio, tanto para o aluno quanto para o professor; distribuição de materiais e equipamentos para a realização dos experimentos; formação inicial e continuada da equipe responsável pela implementação do programa, principalmente professores e mediadores (Andrade, Esteves e Farah Neto, 2009:24).

A tabela seguinte contém resumo das características identificadas nas entrevistas com as diretoras das escolas sobre sua atuação na implementação dos programas BIA e CF. Cada "X" representa a ocorrência de um trecho da entrevista que corresponde a determinada característica. Então, por exemplo, a diretora D1, durante a entrevista, fez duas afirmações que caracterizaram entusiasmo, duas que caracterizaram confiança/otimismo, três que caracterizaram proatividade e assim por diante. Também estavam presentes, na mesma entrevista, uma afirmação que caracterizou falta de entusiasmo, uma que caracterizou desconfiança/pessimismo, duas que demonstraram falta de conhecimento técnico e assim por diante. Quando a célula está em branco, significa que não foi constatada, na entrevista, a característica. Nesse mesmo caso, não se constatou, por exemplo, ocorrência de trecho que demonstrasse energia, tenacidade/persistência, conhecimento técnico, disposição para assumir riscos etc. 
Tabela

Ocorrências de características nas entrevistas com diretoras de escola

\begin{tabular}{|c|c|c|c|c|c|c|c|c|c|c|}
\hline Código & Característica & D1 & $\mathrm{D} 2$ & D3 & D4 & D5 & D6 & D7 & D8 & D9 \\
\hline 1 & Energia & & $x$ & $X X$ & & & & & & $X X$ \\
\hline 2 & Entusiasmo & $X X$ & $x$ & $x X X$ & $X X$ & $x$ & $x$ & $X X X X X X X X X$ & $X X X X$ & $X X$ \\
\hline 3 & Confiança/otimismo & $X X$ & $X X X$ & $x$ & & $x$ & $x$ & $x$ & $X X X$ & \\
\hline 4 & Tenacidade/persistência & & $x$ & & & & & & & $x$ \\
\hline 5 & Conhecimento técnico & & $x$ & $x$ & & $X X X X$ & & & $X X X$ & $X X X$ \\
\hline 6 & Proatividade & $X X X$ & $x$ & $x X$ & $x X$ & $X X X$ & $x$ & $X X$ & $x$ & $x X$ \\
\hline 7 & $\begin{array}{l}\text { Disposição para assumir } \\
\text { riscos }\end{array}$ & & & $x$ & & & & & $x$ & $X X X$ \\
\hline 8 & Comprometimento & & $x$ & & & $X X X$ & & $X X$ & $X X$ & \\
\hline 9 & Criatividade & $X X X X$ & $X X X$ & $X X X X X$ & & $x$ & $x X$ & $X X X X$ & $x$ & $x X X$ \\
\hline 10 & Visão de mundo & & $X X X X X X$ & $x$ & & & & $x$ & $X X$ & $X X X X$ \\
\hline 11 & Jogo de cintura & $X X X$ & $x$ & $x$ & & & & $x$ & $X X X$ & $x$ \\
\hline 12 & $\begin{array}{l}\text { Equilíbrio entre análise e } \\
\text { intuição }\end{array}$ & & & & & & & & & $x X$ \\
\hline 13 & Espírito colaborativo & $x X$ & & $x$ & & & $x X$ & & $x$ & \\
\hline 14 & Espírito integrativo & $x$ & $x X$ & & & $x$ & & & $X X$ & $x$ \\
\hline 15 & Capacidade de delegação & & & & & $x$ & & & $X X$ & \\
\hline 16 & Habilidade política & $x$ & & & & $x$ & & & & $x$ \\
\hline Qtde. & & 8 & 11 & 10 & 2 & 9 & 5 & 7 & 12 & 12 \\
\hline N1 & Falta de energia & & & & $x$ & & & $x$ & & \\
\hline N2 & Falta de entusiasmo & $x$ & & & $X X X X X X X$ & $x$ & $x$ & $x X X$ & & \\
\hline N3 & Desconfiança/pessimismo & $x$ & $x$ & & $x X X$ & $x$ & XX & $x X$ & $X X X$ & $x X$ \\
\hline N4 & $\begin{array}{l}\text { Falta de tenacidade/falta de } \\
\text { persistência }\end{array}$ & & & & $X X X$ & & & & & \\
\hline N5 & $\begin{array}{l}\text { Pouco conhecimento téc- } \\
\text { nico }\end{array}$ & $X X$ & & & $x$ & & $x x$ & $X X$ & & \\
\hline N6 & Falta de proatividade & & $x$ & $x X$ & $X X X X$ & & $x X X$ & $x$ & $x$ & \\
\hline N7 & $\begin{array}{l}\text { Pouca disposição para assu- } \\
\text { mir riscos }\end{array}$ & $x x$ & $\mathrm{x}$ & $x$ & $x x x$ & $x$ & $x$ & & & \\
\hline N8 & Falta de comprometimento & $x$ & & & $x$ & $x$ & & $x$ & & \\
\hline N9 & Falta de criatividade & & & & $x X X$ & & $x X$ & & $x$ & \\
\hline N10 & Pouca visão de mundo & $x$ & & & $x$ & & & & & \\
\hline N11 & Falta de jogo de cintura & & $x$ & & $X X X$ & $x$ & & $x$ & & \\
\hline $\mathrm{N} 12$ & $\begin{array}{l}\text { Desequilíbrio entre análise } \\
\text { e intuição }\end{array}$ & & & & & & & & & \\
\hline $\mathrm{N} 13$ & Pouco espírito colaborativo & & & & $X X$ & $x$ & & & $X X$ & $X X X X$ \\
\hline N14 & Pouco espírito integrativo & & & & $x$ & $x$ & & $X X X X$ & & \\
\hline N15 & Incapacidade de delegação & & $x X$ & & $x X$ & $X X X$ & & $x X$ & & \\
\hline N16 & Inabilidade política & & & & & & & & & \\
\hline Qtde. & & 6 & 5 & 2 & 14 & 8 & 6 & 9 & 4 & 2 \\
\hline
\end{tabular}

Fonte: Elaboração dos autores. 
Entre as características esperadas para empreendedores de políticas públicas, entusiasmo e proatividade foram identificados em todas as diretoras entrevistadas. Criatividade também esteve presente em todos os relatos, com exceção de D4. A presença maciça dessas características mostra que não basta ser criativo, proativo ou entusiasmado para ser champion ou bom empreendedor de políticas públicas. É necessário reunir um conjunto de características para bem implementar os programas, e não apenas algumas delas. Já as características capacidade de delegação e tenacidade/persistência apareceram pouco (apenas em duas entrevistas cada). Também pouco frequente foi o equilíbrio entre análise e intuição, presente apenas em D9.

A pouca capacidade de delegação pode ser explicada pelo fato de que as diretoras podem ser responsabilizadas, até mesmo criminalmente, por determinados atos da gestão escolar. Por exemplo, se não forem encontrados objetos que fazem parte do patrimônio da escola, a diretora tem de responder pelo dano. Diante dessa situação, é natural que ela resista em delegar tarefas a outras pessoas, já que a responsabilidade não é delegada.

Em seu estudo sobre a influência dos champions, Markham (1998) afirmou que eles usam mais táticas cooperativas que de confronto. Portanto, para lidar com suas atividades, existe uma tendência dos champions para o uso de criatividade, otimismo, jogo de cintura, espírito colaborativo e integrativo, enfim, de características que levem a consenso, a cooperação. Ainda citando Markham (1998), os champions parecem ver pontos positivos onde outros não veem. Eles tendem a tentar transformar situações adversas em situações favoráveis. Assim, embora a tenacidade e a persistência sejam características importantes, elas são menos percebidas porque levam à necessidade de insistir e de, muitas vezes, conviver com adversidades.

Quanto à pouca presença, entre as diretoras pesquisadas, do equilíbrio entre análise e intuição, Mintzberg (2010:213-214) oferece uma possível explicação quando observa que há muitos gerentes "que enfatizam, em excesso, a dimensão analítica" e afirma que, "no campo da gestão, a ênfase excessiva na análise costuma tentar ocupar o lugar do juízo". Confirmando o encontrado nesta pesquisa, o autor sugere que são poucos, portanto, os gerentes que conseguem o equilíbrio desejado entre análise e intuição. Não por acaso, a única diretora que demonstrou possuir essa característica também foi a que demonstrou estar mais próxima de um champion e de um empreendedor de políticas públicas ideal.

Ressalte-se que as diretoras que apresentaram essas características menos encontradas (capacidade de delegação, tenacidade/persistência e equilíbrio entre análise e intuição) também demonstraram ter as características mais comuns. Esse fato mostra a aderência dos resultados ao referencial teórico, uma vez que essas diretoras se mostraram mais próximas de champion ou de empreendedor de políticas públicas.

Do lado negativo, ou seja, entre aquelas características que não se espera encontrar em empreendedores de políticas públicas, com exceção de D3, todas as diretoras demonstraram, em algum momento, desconfiança/pessimismo, mesmo aquelas com características positivas predominantes. Isso pode ser explicado pelo momento político em que foi realizada a pesquisa. Várias manifestações pessimistas referiram-se à mudança no governo e à consequente alteração no comando da Secretaria de Educação do Distrito Federal e das diretorias regionais 
de ensino. As próprias diretoras foram exoneradas no final de 2010 e reconduzidas ao cargo no início do ano seguinte. Entretanto, a situação de algumas equipes ainda estava indefinida quando da realização das entrevistas. Também era motivo de preocupação e desânimo a incerteza com relação ao programa CF. As diretoras entrevistadas foram unânimes em afirmar que o programa é ótimo e que desperta bastante interesse nas crianças. Porém, com a mudança de governo, desconfiavam de que ele poderia ser descontinuado.

Observa-se que, em algumas entrevistas, surgem trechos que denotam uma característica positiva e, em outro trecho, da mesma entrevista, aparece uma citação referente à mesma característica, porém negativa. Isso aconteceu, principalmente, com as características entusiasmo, confiança/otimismo e proatividade, e com suas contrapartes negativas (falta de entusiasmo, desconfiança/pessimismo e falta de proatividade). Por exemplo, D7 fez diversas manifestações entusiasmadas quando falou dos programas (BIA e CF), quando falou de como vale a pena e compensa ser diretora da escola e de como isso a deixa feliz. Entretanto, também se ressente da falta de recursos financeiros e das dificuldades para lidar com as famílias, e isso a deixa desanimada. Essa presença das mesmas características, na forma positiva e negativa, numa mesma entrevista, ocorreu, de forma predominante, com as diretoras D5, D6 e D7. Isso pode ser explicado porque, junto com D1, essas diretoras não apresentaram perfil marcante, seja de empreendedor, seja de não empreendedor. Portanto, não podem ser consideradas champions ou empreendedores de políticas públicas. Tal situação confirma o que foi apresentado no referencial teórico.

Observou-se, ainda, diferenciação nos temas que entusiasmam e desanimam essas diretoras. Elas se entusiasmam, em geral, com os programas, principalmente o $\mathrm{CF}$, e com o caráter gratificante do seu trabalho. Já a falta de entusiasmo decorre de falta de recursos e de dificuldades na gestão escolar. Quando as diretoras demonstram confiança e otimismo, os principais motivos são a crença na escola e na eficácia dos programas, a intenção de ver o lado positivo das coisas e o fato de colocarem seus filhos na escola pública, por acreditarem na qualidade do ensino público. Já o pessimismo vem, em geral, da recente troca do governo e de temores ao redor das mudanças pretendidas. Com relação à proatividade, as principais iniciativas dizem respeito a projetos próprios e a adequações ao BIA e ao CF. E a falta de proatividade caracterizou-se na falta de reposição do material do $\mathrm{CF}$, quando necessário.

Os resultados apresentados na tabela permitem reunir as diretoras em três grupos: aquela em que predominaram características negativas (D4); aquelas que demonstram equilíbrio entre características positivas e negativas (D1, D5, D6 e D7) e aquelas em que há mais características positivas (D2, D3, D8 e D9). Dessas quatro, ainda é possível distinguir dois grupos: D2 e D8, que apresentaram várias características negativas (cinco e quatro, respectivamente), e D3 e D9, que apresentaram apenas duas características negativas.

Esses resultados são coerentes com a literatura sobre o tema. Howell e Shea (2006) afirmam que champions são raros nas organizações. Das diretoras pesquisadas, D9 é a que mais se aproxima de champion e de empreendedor de políticas públicas porque é a que apresenta mais características positivas (12) e menos características negativas (duas). Além de possuir as características identificadas com mais frequência nesta pesquisa, tais como entusiasmo, 
proatividade e criatividade, D9 apresentou outras características mais difíceis de encontrar. Por exemplo, podem-se citar habilidade política, equilíbrio entre análise e intuição e disposição para assumir riscos.

Não foi encontrada, nesta pesquisa, diretora que apresentasse todas as características indicadas na literatura. Não seria esperado encontrar alguém com perfil tão completo porque a quantidade de características é muito grande. Ademais, o próprio contexto em que as diretoras se encontram e a forma de implementação top-down dos programas identificada - algumas diretoras teceram comentários acerca da forma top-down de implementação dos programas - podem servir de limite para a atuação dessas gestoras. Assim, criam-se poucas oportunidades para que elas assumam riscos, não há muito espaço para delegação de tarefas nem para o exercício de habilidades políticas. Mesmo assim, os resultados parecem apontar que algumas se sentem mais à vontade que outras para desafiar os limites.

Diversos autores afirmam que champions e empreendedores de políticas públicas contribuem para o sucesso das atividades que desempenham. Por exemplo, Schon, pioneiro nos estudos sobre o tema, afirmou que uma nova ideia encontra um champion ou morre (Markham e Griffin, 1998). Em outro texto, Bartlett e Dibben (2002:119, tradução nossa) afirmam que "o empreendedor do setor público é crítico para a implementação bem-sucedida de recentes iniciativas políticas". Assim, o fato de encontrar essas características nas diretoras de escola entrevistadas significa que, provavelmente, os programas BIA e CF estão sendo mais bem implementados na escola dirigida por D9 que na escola dirigida por D4. Entretanto, não foi escopo desta pesquisa mostrar correlação entre as características e o grau de implementação de programas, mas verificar quais características são encontradas em implementadores de programas governamentais.

Diante dos resultados apresentados e das discussões feitas acerca deles, é possível chegar a diversas conclusões sobre as características das diretoras entrevistadas, bem como apontar temas para novas pesquisas na área de implementação de programas governamentais.

\section{Conclusões}

O principal objetivo desta pesquisa foi identificar e descrever as características de empreendedores de políticas públicas encontradas em implementadores de programas governamentais brasileiros. Os resultados sugerem que a atuação desses implementadores varia bastante no que se refere à posse das características desejadas e necessárias a um empreendedor de políticas públicas. É possível notar diferenças na atuação e no comportamento de diretoras de escolas no que se refere à implementação de programas de governo.

A partir das entrevistas realizadas, foram identificados três tipos de diretoras de escola: aquelas em que predominam características negativas, ou seja, cujos comportamentos e atitudes são contrários aos descritos na literatura para um bom empreendedor de políticas públicas; aquelas em que não se sobressaem, de forma marcante, características positivas ou negativas; e aquelas que demonstraram comportamentos e atitudes que correspondem aos re- 
gistrados no marco teórico como de empreendedores de políticas públicas e champions. Entre as diretoras entrevistadas, D9 é a que mais se aproxima de champion e de empreendedor de políticas públicas.

Com base nesses resultados, a primeira conclusão a que se chega é que existem, entre as diretoras entrevistadas, pessoas que se assemelham a champions e a empreendedores de políticas públicas. Pode-se concluir, também, que as características não são igualmente encontradas entre os implementadores de programas governamentais. Entre as diretoras entrevistadas, algumas características são mais fáceis de encontrar, tais como: entusiasmo, proatividade e criatividade. Entretanto, capacidade de delegação, tenacidade/persistência, equilíbrio entre análise e intuição e disposição para assumir riscos são encontradas com mais dificuldade. E essas últimas seriam as realmente necessárias para caracterizar a atuação de champions e de empreendedores de políticas públicas, porque as diretoras que mostraram ter essas características também tinham aquelas encontradas com mais facilidade. Assim, esses resultados sugerem que o que realmente diferencia um empreendedor de implementação de um não empreendedor são as características encontradas com menos frequência entre as diretoras entrevistadas.

O trabalho teve natureza descritiva e não teve como objetivo fazer inferências sobre a atuação das diretoras e a eficácia da implementação dos programas BIA e CF, nem analisar se esses programas seriam inovações no sistema educacional do Distrito Federal. Mesmo assim, é possível identificar contribuições do estudo para um novo olhar para a implementação de programas governamentais. Aproximando as literaturas de políticas públicas, implementação e inovação, podem-se tecer algumas considerações relevantes para os rumos de teoria e prática na implementação de políticas públicas.

Em primeiro lugar, foi observada na revisão das respectivas literaturas semelhança entre determinadas definições de política pública e algumas definições de inovação no setor público, assim como pontos de convergência entre as fases de inovação e as fases do ciclo de políticas públicas e entre os conceitos de champion (na literatura de inovação), empreendedor de política pública (na literatura de políticas públicas) e gestor eficaz (na literatura de gestão).

Este trabalho, ao encontrar características de champions de inovação e de empreendedores de políticas públicas em implementadores de programas governamentais, traz evidências empíricas de que as semelhanças não são meramente teóricas.

A contribuição do trabalho para o campo teórico é a aproximação de duas literaturas que se debruçam sobre a mesma problemática sem, até o momento, dialogar entre si: a de inovação na gestão pública, na literatura de administração pública, e a de implementação de políticas públicas, na literatura de políticas públicas. A aproximação e o reconhecimento mútuo dessas duas literaturas podem contribuir para mudanças na forma como o processo de implementação é visto e avaliado. Na perspectiva top-down da literatura de implementação, esse processo é tratado como não problemático. Envolve simplesmente cumprir o que foi previamente determinado, de acordo com regras e procedimentos previamente estabelecidos. Mas, se a ação governamental do processo de implementação for vista como envolvendo ino- 
vação na gestão pública, abrem-se novas maneiras de entender este processo e de lidar com ele. Permite entendê-lo como algo não predeterminado que requer qualificações não exclusivamente técnicas para executar com sucesso.

No campo prático, as conclusões deste estudo podem contribuir para o aumento da eficiência e da efetividade da implementação dos programas governamentais, ou seja, sugere novos elementos que não os exclusivamente técnicos a serem considerados na seleção e na capacitação de implementadores de políticas públicas.

Da mesma maneira, abre-se uma gama de novas possibilidades aos pesquisadores de implementação, pois permite que sejam aproveitados, nos estudos sobre implementação, resultados e conclusões de estudos sobre inovação. Assim, este trabalho contribui para o avanço dos estudos sobre implementação que, como se sabe, é a etapa menos pesquisada do ciclo de políticas públicas. A possibilidade de apropriar-se dos resultados de estudos sobre inovação (quando cabível) seria bastante útil para ampliar o conhecimento sobre implementação.

A partir dos resultados obtidos, além das contribuições já descritas, vislumbram-se algumas contribuições para futuros estudos. A primeira delas é a conexão que parece existir entre empreendedores de políticas públicas, inovação e implementadores de programas governamentais. A literatura sobre champions vem da área de inovação. Entretanto, aproximando-se literaturas distintas, verificou-se que há pontos em comum entre as fases de inovação e as do ciclo de políticas públicas e há semelhanças entre os conceitos de champions, empreendedores de políticas públicas e implementadores de programas governamentais. Uma possibilidade a ser testada em futuras pesquisas é a proposição de que a implementação de um programa governamental seria um tipo de inovação ou de difusão de inovação. Considera-se que uma pesquisa nesse sentido seria de grande utilidade porque, se for comprovado que a implementação é um tipo de inovação, os resultados dos trabalhos de uma área poderiam ser aproveitados para a outra, criando intercâmbio benéfico e aumento de conhecimento, tanto para os pesquisadores de inovação quanto para os pesquisadores de implementação.

Outra sugestão de pesquisa acerca do papel de empreendedores de implementação seria a realização de novos trabalhos que tenham por objetivo estudar a correlação entre as características de champions e empreendedores de políticas públicas e o grau de implementação de programas. Se essa correlação for comprovada, o estudo poderia demonstrar a efetividade de designar pessoas com características de champions para implementar programas governamentais, pois essa designação levaria à melhoria na implementação desses programas.

Por fim, os resultados desta pesquisa indicaram que a implementação de programas está inserida em quadro político bastante amplo, sendo influenciada, por exemplo, por mudanças governamentais. Diante disso, seria pertinente fazer paralelo entre os fluxos identificados por Kingdon (1995) e Zahariadis (2003) na fase de formulação de políticas públicas com eventuais fluxos na fase de implementação. Os resultados da pesquisa aqui descrita sugerem que, da mesma maneira que mudanças no fluxo de politics podem abrir (e fechar) janelas de oportunidade para incluir assuntos na agenda política, na fase de formulação de políticas públicas, mudanças no fluxo de politics (como mudança de governo ou mudança de dirigentes) podem impedir, bloquear ou dificultar a continuidade da implementação de programas e 
projetos públicos em andamento. Conclui-se, portanto, que politics parece ser um dos fluxos envolvidos também em implementação. Assim, um possível tema para futuras pesquisas seria verificar, a exemplo do que fizeram Kingdon (1995) e Zahariadis (2003) para a formulação, a existência de fluxos no processo de implementação de políticas públicas. No caso de eles existirem, também seria interessante identificar quais seriam esses fluxos. Um trabalho desse tipo contribuiria para o avanço do conhecimento, não somente sobre o fenômeno de empreendedores de implementação de programas governamentais, mas sobre o próprio fenômeno do processo de implementação.

\section{Referências}

ANDRADE, Eliane R.; ESTEVES, Luiz C. G.; FARAH NETO, Miguel. Programa Ciência em Foco: diagnóstico do impacto inicial. Brasília: Epocca Editorial, 2009.

BARDACH, Eugene. The implementation game. Cambridge, MA: MIT Press, 1977.

BARTLETT, Dean; DIBBEN, Pauline. Public sector innovation and entrepreneurship: case studies from local government. Local government studies, London, v. 28, n. 4, p. 107-121, 2002.

BRYSON, John M.; CROSBY, Barbara C.; STONE, Melissa M. The design and implementation of cross-sector collaborations: propositions from the literature. Public Administration Review, special issue, p. 44-55, Dec. 2006.

CHAKRABARTI, Alok K. The role of champion in product innovation. California Management Review, v. 17, n. 2, p. 58-62, 1974.

DISTRITO FEDERAL. Secretaria de Estado de Educação. Regimento interno da Secretaria de Estado de Educação do Distrito Federal. 1. ed. Brasília, 2009.

DISTRITO FEDERAL. Secretaria de Estado de Educação. Subsecretaria de Educação Pública. Orientações gerais para o ensino fundamental de 9 anos: Bloco Inicial de Alfabetização. Brasília, 2005.

EXWORTHY, Mark; BERNEY, Lee; POWELL, Martin. How great expectations in Westminster may be dashed locally: the local implementation of national policy on health inequalities. Policy \& Politics, v. 30, n. 1, p. 79-96, 2002.

FARIA, Carlos A. P. A política da avaliação de políticas públicas. Revista Brasileira de Ciências Sociais, São Paulo, v. 20, n. 59, p. 97-169, 2005.

FREY, Klaus. Políticas públicas: um debate conceitual e reflexões referentes à prática da análise de políticas públicas no Brasil. Planejamento e Políticas Públicas, Brasília, n. 21, p. 211-259, 2000.

HILL, Michael; HUPE, Peter. Implementing public policy. Londres: Sage Publications, 2002.

HOLANDA FERREIRA, Aurélio B. Novo dicionário da língua portuguesa. 1. ed. Rio de Janeiro: Nova Fronteira, 1975. 
HOWELL, Jane M.; SHEA, Christine M. Effects of champion behavior, team potency, and external communication activities on predicting team performance. Group \& Organization Management, v. 31, n. 2, p. 180-211, 2006.

HOWELL, Jane M.; SHEA, Christine M.; HIGGINS, Christopher A. Champions of product innovations: defining, developing, and validating a measure of champion behavior. Journal of Business Venturing, v. 20, p. 641-661, 2005.

KINGDON, John W. Agendas, alternatives, and public policies. 2. ed. Nova York: HarperCollins College Publishers, 1995.

KOBRAK, Peter. The social responsibilities of a public entrepreneur. Administration \& Society, v. 28, n. 2, p. 205-237, 1996.

LIPSKY, Michael. Street-level bureaucracy. Nova York: Russell Sage Foundation, 1980.

MARKHAM, Stephen K. A longitudinal examination of how champions influence others to support their projects. Journal of Product Innovation Management, v.15, n. 6, p. 490-504, 1998.

MARKHAM, Stephen K.; GRIFFIN, Abbie. The breakfast of champions: associations between champions and product development environments, practices and performance. Journal of Product Innovation Management, v.15, n. 6, p. 436-454, 1998.

MATLAND, Richard E. Synthesizing the implementation literature: the ambiguity-conflict model of policy implementation. Journal of Public Administration, Houston, v. 5, n. 2. p. 145-174, Apr. 1995.

MENICUCCI, Telma. A implementação da reforma sanitária: a formação de uma política. Estado da Arte da Pesquisa em Políticas Públicas. In: HOCHMAN, Gilberto; ARRETCHE, Marta; MARQUES, Eduardo (Org.). Políticas públicas no Brasil. Rio de Janeiro: Fiocruz, 2007. p. 303-325.

MINTZBERG, Henry. Managing: desvendando o dia a dia da gestão. Porto Alegre: Bookman, 2010.

NEVES, Clarissa E. B.; NEVES, Fabrício M. Pesquisa e inovação: novos desafios para a educação superior no Brasil e na Alemanha. Caderno CRH, Salvador, v. 24, n. 63, p. 481-501, 2011.

OLIVEIRA, José A. P. Desafios do planejamento em políticas públicas: diferentes visões e práticas. Revista de Administração Pública, Rio de Janeiro, v. 40, n. 1, p. 273-288, 2006.

OLLAIK, Leila G.; MEDEIROS, Janann J. Instrumentos governamentais: reflexões para uma agenda de pesquisas sobre implementação de políticas públicas no Brasil. Revista de Administração Pública, Rio de Janeiro, v. 45, n. 6, p. 1943-1967, 2011.

OSZLAK, Oscar; O’DONNELL, Guillermo. Estado y políticas estatales en América Latina: hacia una estrategia de investigación. Buenos Aires: Clacso, 1976.

PEREZ, José R. R. Por que pesquisar implementação de políticas educacionais atualmente? Educação \& Sociedade, Campinas, v. 31, n. 113, p. 1179-1193, 2010.

PRESSMAN, Jeffrey L.; WILDAVSKY, Aaron. Implementation. Berkeley: University of California Press, 1973. 
ROGERS, Everett M. Diffusion of innovations. 4. ed. Nova York: The Free Press, 1995.

SHANE, Scott; VENKATARAMAN, Shane; MACMILLAN, Ian. Cultural differences in innovation championing strategies. Journal of Management, v. 21, n. 5, p. 931-952, 1995.

SOUZA, Celina. Estado da arte da pesquisa em políticas públicas. In: HOCHMAN, Gilberto; ARRETCHE, Marta; MARQUES, Eduardo (Org.). Políticas públicas no Brasil. Rio de Janeiro: Fiocruz, 2007, p. 65-86.

SOUZA, Celina. Políticas públicas: uma revisão da literatura. Sociologias, v. 8, n. 16, p. 20-45, 2006.

SPINK, Peter. A inovação na perspectiva dos inovadores. In: JACOBI, Pedro; PINHO, José A. (Org.). Inovação no campo da gestão pública local: novos desafios, novos patamares. São Paulo: FGV Editora, 2006. p. 23-39.

THEODOULOU, Stella Z. How public policy is made. In: THEODOULOU, Stella Z.; CAHN, Matthew A. Public policy: the essential readings. New Jersey: Prentice Hall, 1995. p. 86-96.

WEISS, Carol. Evaluation: methods for studying programs and policies. 2. ed. New Jersey: Prentice-Hall, 1998.

WINDRUM, Paul; KOCH, Per (Ed.). Innovation in public sector services: entrepreneurship, creativity and management. Cheltenham, UK: Edward Elgar Publishing, 2008.

ZAHARIADIS, Nikolaos. Ambiguity \& choice in public policy. Washington, DC: Georgetown University Press, 2003.

Maria Lúcia de Oliveira Feliciano de Lima é auditora federal de Controle Externo do Tribunal de Contas da União (TCU). E-mail: mluciaofl@yahoo.com.br.

Janann Joslin Medeiros é professora adjunta da Universidade de Brasília (UnB). E-mail: janmedeiros@ gmail.com. 